\title{
EVALUATION OF RESULTS AND COMPLICATIONS FROM ARTHROSCOPIC SUTURE OF SLAP LESIONS
}

\author{
Alberto Naoki Miyazaki ${ }^{1}$, Marcelo Fregoneze ${ }^{2}$, Pedro Doneux Santos ${ }^{3}$, Luciana Andrade da Silva ${ }^{3}$, Guilherme do Val Sella ${ }^{3}$, André \\ Lopes Soares ${ }^{4}$, Adriano Fernando Mendes Junior ${ }^{4}$, Sérgio Luiz Checchia ${ }^{5}$
}

\begin{abstract}
Objective: To evaluate the results and complications from arthroscopic suturing of SLAP lesions. Methods: Seventy-one patients who underwent arthroscopic suturing of SLAP lesions between July 1995 and May 2008 were evaluated. The procedures were performed by the Shoulder and Elbow Surgery Group of the Department of Orthopedics and Traumatology, Fernandinho Simonsen Wing, Santa Casa de São Paulo, Brazil. Associated lesions were seen in 68 of the 71 patients evaluated (96\%), and the other three (4\%) had SLAP lesions alone. Results: The associated lesions most frequently found in the patients under 40 years of age were labral lesions (69\%), while
\end{abstract}

in patients aged 40 years or over, impact syndrome with or without rotator cuff injury was the most commonly associated condition (71.4\%). According to the UCLA method, $79 \%$ of our results (56 cases) were good or excellent. Postoperative complications occurred in 15 cases $(21 \%)$; among these, the most common was the presence of residual pain (46.6\%), followed by adhesive capsulitis (33.3\%). Conclusions: There was a great association between SLAP lesions and other shoulder lesions, which varied according to the patients' age groups. Arthroscopic suturing of the SLAP lesions provided excellent results in the majority of the cases, but complications occurred in $21 \%$.

Keywords - Shoulder; Arthroscopy; Complications

\section{INTRODUCTION}

The advent and development of arthroscopy as a diagnostic and therapeutic method for patients presenting shoulder pain and functional impotence has made it more common to diagnose lesions of the superior glenoid labrum ${ }^{(1-7)}$.

Injuries to the superior glenoid labrum were first described by Andrews et $\mathrm{al}^{(1)}$ in 1985, among baseball pi- tchers. In 1990, Snyder et $\mathrm{al}^{(8)}$ defined SLAP (superior labrum anterior and posterior) injuries and classified them into four types according to their arthroscopic assessments. In 1995, Maffet et $\mathrm{al}^{(4)}$ added type $\mathrm{V}$ to Snyder's classification, corresponding to superior glenoid labrum injuries that extended anteriorly. In 1998, Morgan et $\mathrm{al}^{(5)}$ subdivided type II into three subtypes, according to the location of the superior glenoid labrum injury: anterior, posterior or combined.

1 - Assistant Professor and Head of the Shoulder and Elbow Surgery Group, Department of Orthopedics and Traumatology, School of Medical Sciences, Santa Casa de São Paulo, São Paulo, Brazil.

2 - Assistant Professor and Attending Physician in the Shoulder and Elbow Surgery Group, Department of Orthopedics and Traumatology, School of Medical Sciences, Santa Casa de São Paulo, São Paulo, Brazil.

3 - Attending Physician in the Shoulder and Elbow Surgery Group, Department of Orthopedics and Traumatology, School of Medical Sciences, Santa Casa de São Paulo, São Paulo, Brazil.

4 - Trainee in the Shoulder and Elbow Surgery Group, Department of Orthopedics and Traumatology, School of Medical Sciences, Santa Casa de São Paulo, São Paulo, Brazil.

5 - Adjunct Professor, Academic Consultant and Member of the Shoulder and Elbow Surgery Group, Department of Orthopedics and Traumatology, School of Medical Sciences, Santa Casa de São Paulo, São Paulo, Brazil.

Work performed in the Department of Orthopedics and Traumatology, "Fernandinho Simonsen” Wing, School of Medical Sciences, Santa Casa de São Paulo, São Paulo, Brazil. Director: Prof. Dr. Osmar Avanzi.

Correspondence: R. Dr. Cesário Mota Jr, 112 - Vila Buarque - 01221-020 - São Paulo, SP. E-mail: ombro@ombro.med.br

Work received for publication: February 17, 2010; accepted for publication: June 14, 2010. 
The etiology of SLAP lesions is uncertain, although the literature describes the following as possible causes: compression forces applied to the glenohumeral joint after a fall with the shoulder in a position of abduction and flexion; and tension forces applied to the arm, caused by traction mechanisms on the arm, or as a result of throwing movements, observed especially in baseball players ${ }^{(1,2,9,10)}$.

These injuries may be presented separately or in association with an impact syndrome, with or without rotator cuff injuries, anterior instability, posterointernal impact with or without a lesion on the joint face of the tendon of the supraspinatus muscle, chondromalacia of the humeral head or acromioclavicular arthrosis ${ }^{(9-11)}$.

Since SLAP lesions were first described, several types of treatment have been proposed. Conservative treatment does not provide healing of the lesion ${ }^{(12)}$. Arthroscopic debridement is indicated, and is performed on type I lesions and in the presence of labral deinsertion. However, this last type has not shown good results from long-term follow-up, and arthroscopic repair of these lesions is considered to be the preferred treatment ${ }^{(2,8-14)}$.

Some studies have shown that after athletes who make throwing actions have undergone arthroscopic repair on SLAP lesions, they do not return to the same level of activity and show dissatisfaction with this type of treatment ${ }^{(10,15,16)}$. Sutures on SLAP lesions, like all surgical procedures on the shoulder, are subject to complications such as adhesive capsulitis, formation of granuloma in the suture ${ }^{(17)}$, compression of the suprascapular nerve and loosening, breakage or intra-articular positioning of the implant ${ }^{(18,19)}$.

The objective of this study was to assess the results and complications from treatment of SLAP lesions using labral reinsertion techniques by means of arthroscopy.

\section{METHODS}

Seventy-one patients who underwent arthroscopic suturing of SLAP lesions between July 1995 and May 2008 were evaluated. The operations were performed by the Shoulder and Elbow Group of the Department of Orthopedics and Traumatology, School of Medical Sciences, Santa Casa de Misericórdia, Fernandinho Simonsen Wing, São Paulo (Table 1).

Rev Bras Ortop. 2011;46(1):51-6
Table 1 - Data on patients according to age group

\begin{tabular}{|c|c|c|}
\hline & Group 1 & Group 2 \\
\hline & $<40$ years & $\geq \mathbf{4 0}$ years \\
\hline No. of patients & 43 & 28 \\
\hline Mean age & 27 & 52 \\
\hline \multicolumn{3}{|l|}{ Sex } \\
\hline Male & 41 & 24 \\
\hline Female & 2 & 4 \\
\hline Dominant limb & 37 (86\%) & $20(71.4 \%)$ \\
\hline \multicolumn{3}{|l|}{ Etiology } \\
\hline Traumatic & $26(60.5 \%)$ & $14(50 \%)$ \\
\hline Non-traumatic & $17(39.5 \%)$ & $14(50 \%)$ \\
\hline Sports activity & $33(81.4 \%)$ & $20(71.4 \%)$ \\
\hline Professional athlete & 5 & 0 \\
\hline \multicolumn{3}{|l|}{ SLAP type } \\
\hline Type II & $13(30.3 \%)$ & $23(82.1 \%)$ \\
\hline Type III & $1(2.3 \%)$ & 0 \\
\hline Type IV & $1(2.3 \%)$ & 0 \\
\hline Type V & $27(62.8 \%)$ & $5(17.9 \%)$ \\
\hline Indeterminate & $1(2.3 \%)$ & 0 \\
\hline SLAP alone $3(7 \%)$ & 0 & \\
\hline \multicolumn{3}{|l|}{ Associated lesions } \\
\hline Labral lesions & $30(69.8 \%)$ & $6(21.4 \%)$ \\
\hline Impact syndrome/RCL & $3(7 \%)$ & $20(71.4 \%)$ \\
\hline $\mathrm{AC}$ arthrosis & $3(7 \%)$ & $10(35.7 \%)$ \\
\hline $\begin{array}{l}\text { Incipient shoulder } \\
\text { arthrosis }\end{array}$ & $1(2.3 \%)$ & $4(14.3 \%)$ \\
\hline Other lesions & $8(18.6 \%)$ & $5(17.8 \%)$ \\
\hline
\end{tabular}

Legend: $\mathrm{RCL}$ - rotator cuff lesion; $\mathrm{AC}$ - acromioclavicular. Source: SAME - ISCMSP.

All patients with a diagnosis of SLAP lesion who were treated by means of suturing using arthroscopy were included in this study. Demographic data, clinical signs and intraoperative findings were retrieved from the patients' medical files.

The length of the follow-up ranged from 10 to 134 months, with a mean of 49 months. The patients' mean age was 37 years, with a range from 13 to 72 years. Male patients predominated, accounting for $90 \%$ of the cases (64 patients), and the dominant limb was affected in the cases of 57 patients $(80 \%)$ (Table 1).

The time that elapsed from the start of the symptoms to the date when the surgery was performed ranged from one week to 240 months, with a mean of 36 months. Thirty-seven patients $(52 \%)$ had previously undergone physiotherapy treatment. There were reports of trauma preceding the symptoms in the ca- 
ses of 40 patients (56\%). Fifty-three patients $(75 \%)$ practiced sports activities, and five were professional sports players $(7 \%)$.

All the patients underwent a physical examination and magnetic resonance imaging on the shoulder before the operation (Figure 1). Out of the 71 patients evaluated, $68(96 \%)$ presented associated lesions, and only three cases $(4 \%)$ presented a SLAP lesion alone. The lesions found to be associated with SLAP lesions were: impact syndrome, with or without rotator cuff injuries, calcareous tendinitis, supraglenoid cyst, instability, posterointernal impact and acromioclavicular and glenohumeral arthrosis (Table 1).

The classification used for the SLAP lesions was the one proposed by Snyder et $\mathrm{al}^{(8)}$ and modified by Maffet et $\mathrm{al}^{(4)}$. Type II was found most frequently, corresponding to 36 cases (51\%), followed by type $\mathrm{V}$ with 32 cases $(45 \%)$. Among the remaining three lesions, one was classified as type III, another as type IV and the last had a lesion that was not characterized by this classification system (lesion of superior labrum with extensive anterior and posterior involvement). Among the three patients who presented a SLAP lesion alone, one was classified as type IV and two as type II (Table 1).

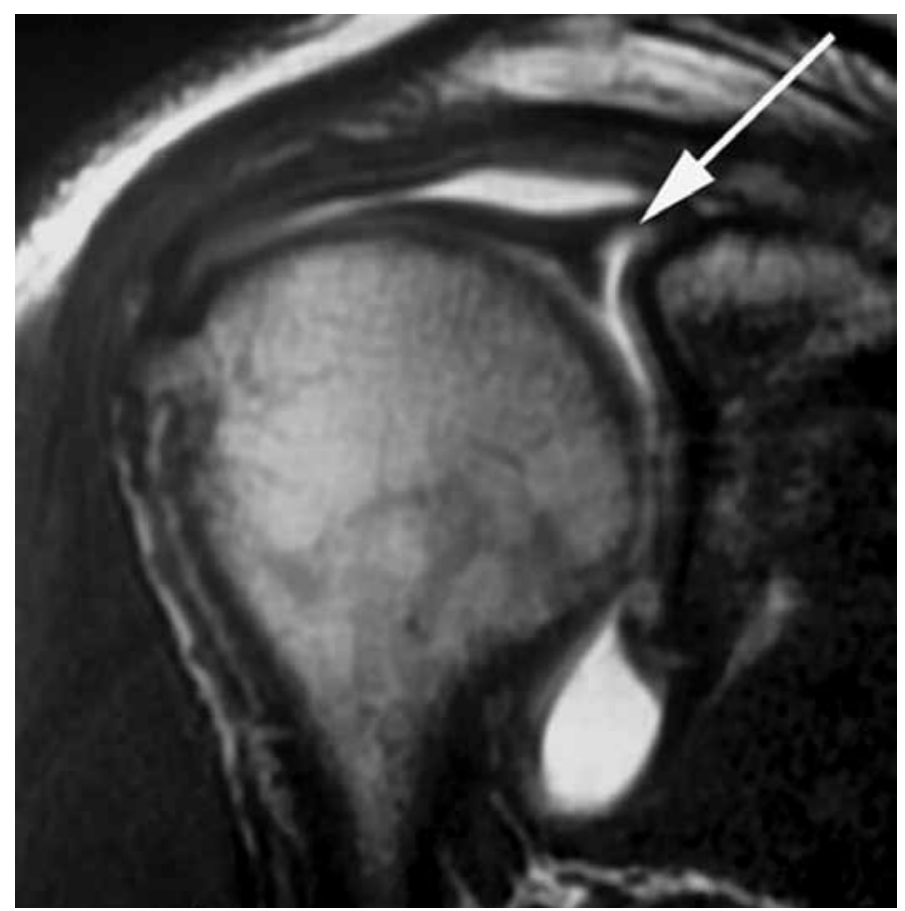

Figure 1 - Image showing coronal slice from magnetic arthro-resonance imaging of the right shoulder of a patient with a lesion of the superior glenoid labrum (white arrow).
The patients were treated arthroscopically, with suturing of the SLAP lesion (Figure 2) and treatment of the associated lesions. Three patients who underwent arthroscopic suturing of the SLAP lesion underwent open surgery to treat their associated lesions because that was the surgical approach taken at the time of their operations.

The patients were divided into two groups according to their age group: group 1 - patients aged under 40 years; group 2 - patients aged 40 years and over. The preoperative data on the patients were distributed according to this division and are shown in Table 1.

The method chosen for assessing the patients after
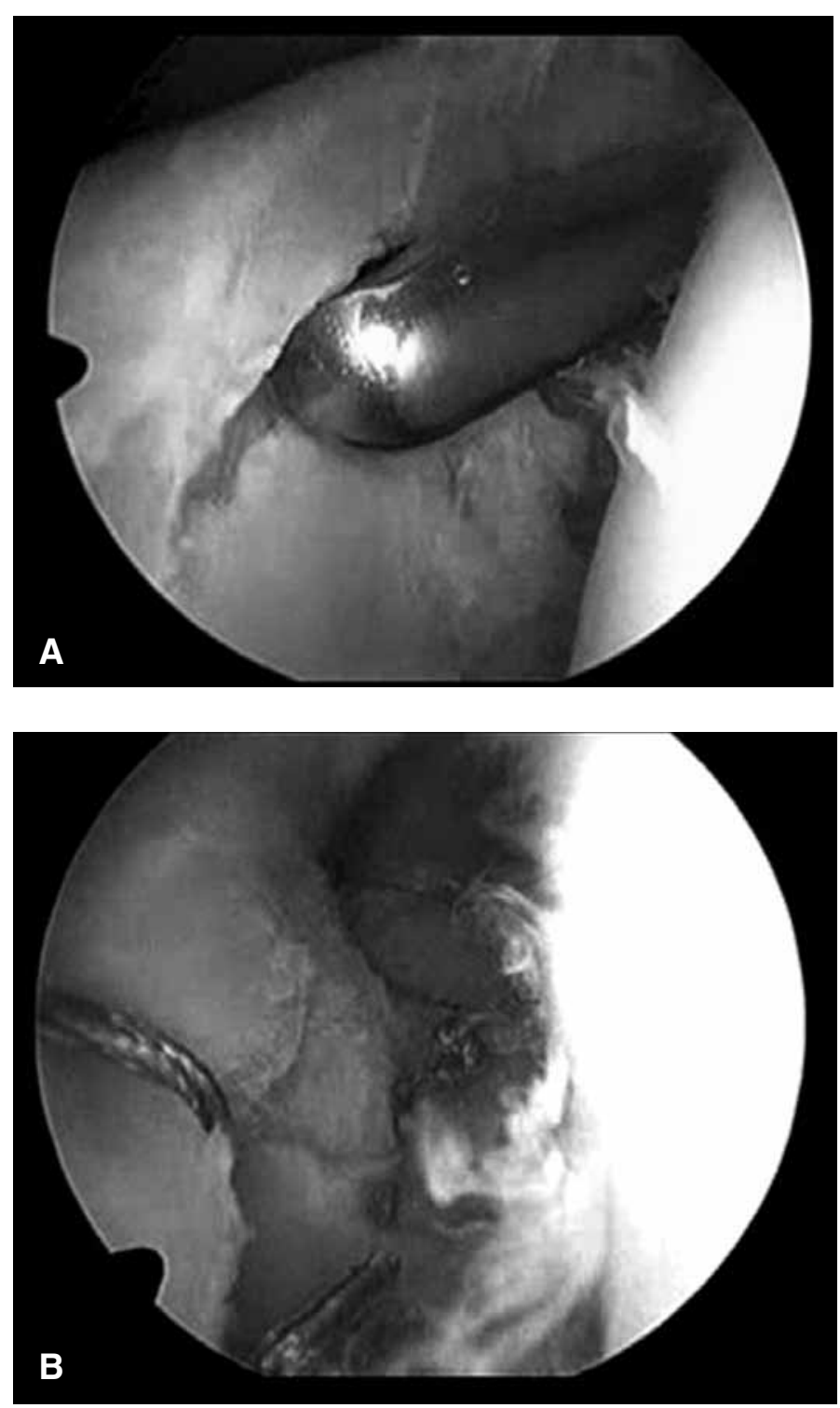

Figure 2 - Arthroscopic image of the right shoulder (posterior view), showing deinsertion of the superior glenoid labrum $(A)$ and after suturing of the lesion (B). 
the operation was based on the UCLA criteria (University of California at Los Angeles) ${ }^{(20)}$. Joint mobility was assessed in accordance with the guidance of the American Shoulder and Elbow Society (ASES) ${ }^{(21)}$. The statistical analysis was done using the SPSS software (Statistical Package for Social Sciences), version 13.0, taking the significance level of 5\% (p $<0.05$ ). Fisher's exact test was used to compare the associated lesions, results and complications between groups 1 and 2 .

\section{RESULTS}

Out of the 71 patients evaluated, $68(96 \%)$ presented associated lesions, of which 36 cases $(51 \%)$ were related to glenohumeral instability. Among the patients aged under 40 years (group 1), 69.8\% (30 cases) presented associations with labral lesions, while among those aged 40 years and over (group 2), 71.4\% (20 cases) presented associations with impact syndrome with or without rotator cuff lesion, with a statistically significant difference between the groups $(p<0.001)$ (Table 1). According to the UCLA method, 40 patients (57\%) achieved results that were considered excellent, $16(22 \%)$ had good results, eight had fair results (11\%) and seven had poor results $(10 \%)$, thus totaling 56 (79\%) with good or excellent results and $15(21 \%)$ with unsatisfactory results, among whom three (4\%) did not return to work. Among the patients in group 1 ( $<40$ years), 79.1\% (34 cases) had good or excellent results, while among the patients in group 2 ( $\geq 40$ years), $78.6 \%$ (22 cases) had good or excellent results, which was a difference without statistical significance $(\mathrm{p}=0.45)$ (Table 2).

Complications were observed in 15 patients $(21 \%)$, of which: seven cases ( $46.6 \%$ of the complications) had residual pain; five cases $(33.3 \%)$ had adhesive capsulitis; one case $(6.7 \%)$ had loosening of the anchor, which evolved with functional limitation of the shoulder; one case $(6.7 \%)$ did not return to the same levels of sports activity; and one case (6.7\%) evolved with infection and post-infection arthrosis (Table 2). Among the patients in group 1 ( $<40$ years), $20.9 \%$ (nine cases) evolved with complications; and among the patients in group 2 ( $\geq 40$ years), $21.4 \%$ ( six cases) evolved with complications, which was a difference without statistical significance $(p=0.59)$. Adhesive
Table 2 - Results from postoperative assessment according to age group distribution.

\begin{tabular}{c|c|c}
\hline & Group 1 & Group 2 \\
\hline Results (UCLA) & $<\mathbf{4 0}$ years & $\geq \mathbf{4 0}$ years \\
\hline Excellent & $26(60.5 \%)$ & $14(50 \%)$ \\
\hline Good & $8(18.6 \%)$ & $8(28.6 \%)$ \\
\hline Fair & $4(9.3 \%)$ & $4(14.3 \%)$ \\
\hline Poor & $5(11.6 \%)$ & $2(7.1 \%)$ \\
\hline Complications & & 0 \\
\hline Adhesive capsulitis & 5 & 5 \\
\hline Residual pain & 2 & 0 \\
\hline Non-return to previous & 1 & 0 \\
activity level & 1 & $6(21.4 \%)$ \\
\hline Anchor loosening & 0 &
\end{tabular}

Caption: Activ. - activity

Source: SAME - ISCMSP.

capsulitis was responsible for $55.6 \%$ of the complications in group 1, while residual pain accounted for $83.3 \%$ of the complications in group 2 (Table 2).

All the 15 patients $(21 \%)$ who evolved with complications presented associated lesions, and nine of these had more than one associated lesion (Table 3). Among the five athletes, three $(60 \%)$ evolved with complications: two (40\%) with adhesive capsulitis and one $(20 \%)$ did not return to the same level of activity. The three patients who did not present associated lesions returned to work and achieved results that were considered excellent according to the UCLA method.

\section{DISCUSSION}

Our sample showed, in agreement with the literature, that SLAP lesions were more frequent among males (90\%), affected the dominant limb more (80\%) and were generally secondary to a traumatic mechanism $(56 \%)^{(7,9,22-25)}$. According to Snyder's classification, as modified by Maffet, type II (51\%) was found most frequently, as also shown in other studies ${ }^{(7,9,24)}$. However, we found that the patients aged under 40 years (group 1) most frequently presented type V lesions $(30.3 \%)$ (Table 1$)$. The mean age of the patients in this study was 37 years, which was higher than the mean age found in other studies. This is perhaps 
Table 3 - Patients with postoperative complications.

\begin{tabular}{|c|c|c|c|c|c|c|c|c|}
\hline No. & Sex & Age & Athlete & Associated lesions & $\begin{array}{l}\text { SLAP } \\
\text { type }\end{array}$ & $\begin{array}{l}\text { Length of follow-up } \\
\text { (months) }\end{array}$ & UCLA & Complication \\
\hline 1 & $\mathrm{M}$ & 58 & & $\mathrm{IS}+$ Inst + GHA & II & 13 & 24 & Residual pain \\
\hline 2 & M & 17 & & Inst & V & 22 & 26 & Residual pain \\
\hline 4 & $\mathrm{M}$ & 39 & & Inst & V & 10 & 17 & $A C$ \\
\hline 8 & $\mathrm{~F}$ & 47 & & $\mathrm{CT}+\mathrm{RCL}$ & II & 12 & 24 & Residual pain \\
\hline 11 & $M$ & 32 & & Inst + GHA & V & 72 & 20 & Residual pain \\
\hline 18 & $\mathrm{M}$ & 35 & & $\mathrm{PII}+\mathrm{ACA}$ & II & 10 & 14 & $A C$ \\
\hline 19 & $\mathrm{~F}$ & 67 & & $\mathrm{IS}+\mathrm{RCL}+\mathrm{ACA}$ & II & 13 & 17 & Residual pain \\
\hline 24 & $M$ & 54 & & $\mathrm{IS}+\mathrm{RCL}+\mathrm{ACA}$ & II & 62 & 23 & Residual pain \\
\hline 26 & $M$ & 34 & & Inst & II & 101 & 25 & $A C$ \\
\hline 32 & $M$ & 18 & $\mathrm{Y}$ & IS + Inst & II & 13 & 26 & $\begin{array}{c}\text { Non-return to previous } \\
\text { activity level }\end{array}$ \\
\hline 44 & $M$ & 40 & & $\mathrm{RCL}$ & II & 14 & 24 & Residual pain \\
\hline 56 & $\mathrm{~F}$ & 26 & $\mathrm{Y}$ & PII & II & 21 & 12 & $A C$ \\
\hline 59 & $M$ & 53 & & Inst + RCL+ ACA & V & 64 & 5 & Infection \\
\hline 61 & M & 24 & & Inst & II & 13 & 23 & Loosening of anchor \\
\hline 65 & $M$ & 28 & $\mathrm{Y}$ & Inst + PII & IV & 21 & 13 & $A C$ \\
\hline
\end{tabular}

Legend: M - male; F - female; Y - yes; IS - impact syndrome; Inst - instability; ACA - acromioclavicular arthrosis; GHA - glenohumeral arthrosis; PII - posterointernal impact; CT - calcareous tendinitis; $\mathrm{RCL}$ - rotator cuff lesion; $\mathrm{AC}$ - adhesive capsulitis.

Source: SAME - ISCMSP.

explained by the low percentage of SLAP lesions alone $(4 \%)$ in our sample, which affected younger patients $^{(22,23,26-28)}$.

SLAP lesions are often associated with other lesions in the shoulder ${ }^{(24,29)}$. Snyder et al ${ }^{(9)}$ reported that $62 \%$ of their SLAP cases presented associated lesions, and the most frequent of these were rotator cuff lesions $(40 \%)$, followed by anterior labral lesions $(22 \%)$. From an analysis on 139 SLAP cases, Kim et $\mathrm{al}^{(30)}$ showed that $88 \%$ presented associated lesions, and the frequency of these lesions varied according to the patients' ages: patients aged 40 years or over had a greater association with rotator cuff lesions and arthrosis; those aged under 40 years had a greater association with Bankart lesions. In our study, we found that $96 \%$ of the cases of SLAP lesions presented associated lesions, among which those relating to shoulder instability (51\%) were the most frequent. However, when we divided the patients into two groups according to age, we found that the patients aged 40 years or over had more association with impact syndrome with or without rotator cuff lesion (71.4\%), while those aged under 40 years had more association with labral lesions $(69.8 \%)$, which was a statistically significant difference, thereby confirming the data published by Kim et $\mathrm{al}^{(30)}$.

Arthroscopic repair of SLAP lesions, in cases of labral deinsertion, has been considered to be the preferred treatment, with good results obtained ${ }^{(2,14,22-24)}$. Some authors have reported that patients undergoing SLAP lesion repair may evolve with complications that compromise the final result from the treatment, including: residual pain, adhesive capsulitis and non-return to previous activity level ${ }^{(10,25,26,31)}$. The risk factors for these unsatisfactory results are still unknown. In a retrospective study, Khetia et $\mathrm{al}^{(31)}$ showed that all the 21 patients evaluated after SLAP lesion repair evolved with residual pain and stiffness during the postoperative period, thus suggesting that there should be greater caution in treating this lesion among patients aged 40 years or over. Franceschi et $\mathrm{al}^{(32)}$ showed that there were no advantages in repairing SLAP lesions in patients over the age of 50 years when these cases were associated with rotator cuff lesions, and that biceps tenotomy provided better results in these cases. Boileau et $\mathrm{al}^{(10)}$ showed that tenodesis of the biceps allowed a return to the same level of sports activity, compared with arthroscopic repair of SLAP lesions. Brockmeier et $\mathrm{al}^{(24)}$ suggested that the presence of lesions associated with SLAP lesions modified 
the postoperative rehabilitation protocol and could interfere with the final clinical result. Other authors have shown that treatment of the associated lesions concomitantly with SLAP lesion repair presented results that were similar to those from repair of SLAP lesions alone ${ }^{(27,28)}$.

According to the UCLA assessment method, our study showed that 56 patients $(79 \%)$ achieved good or excellent results, while $15(21 \%)$ had unsatisfactory results. There was no statistically significant difference in these results according to age, between groups 1 and 2. Complications were observed in 15 cases $(21 \%)$, and the most frequent of these were residual pain $(47 \%)$ and adhesive capsulitis (33\%), thus confirming what some other authors had described ${ }^{(25,26,31)}$. There was no statistically significant difference in relation to the incidence of complications between groups 1 and 2, but we observed that the most fre-

\section{REFERENCES}

1. Andrews JR, Carson WG Jr, McLeod WD. Glenoid labrum tears related to the long head of the biceps. Am J Sports Med. 1985;13(5):337-41.

2. Park JH, Lee YS, Wang JH, Noh HK, Kim JG. Outcome of the isolated SLAP lesions and analysis of the results according to the injury mechanisms. Knee Surg Sports Traumatol Arthrosc. 2008;16(5):511-5.

3. Enad JG, Gaines RJ, White SM, Kurtz CA. Arthroscopic superior labrum anterior-posterior repair in military patients. J Shoulder Elbow Surg. 2007;16(3):300-5.

4. Maffet MW, Gartsman GM, Moseley B. Superior labrum-biceps tendon complex lesions of the shoulder. Am J Sports Med. 1995;23(1):93-8.

5. Morgan CD, Burkhart SS, Palmeri M, Gillespie M. Type II SLAP lesions: three subtypes and their relationships to superior instability and rotator cuff tears. Arthroscopy. 1998;14(6):553-65.

6. Tomlinson RJ Jr, Glousman RE. Arthroscopic debridement of glenoid labral tears in athletes. Arthroscopy. 1995;11(1):42-51.

7. Godinho GG, Freitas JMA, Leite LMB, Pina ERM. Lesões SLAP no ombro. Rev Bras Ortop. 1998;33(5):345-52.

8. Snyder SJ, Karzel RP, Del Pizzo W, Ferkel RD, Friedman MJ. SLAP lesions of the shoulder. Arthroscopy. 1990;6(4):274-9.

9. Snyder SJ, Banas MP, Karzel RP. An analysis of 140 injuries to the superior glenoid labrum. J Shoulder Elbow Surg. 1995;4(4):243-8

10. Boileau P, Parratte S, Chuinard C, Roussanne Y, Shia D, Bicknell R.Arthroscopic treatment of isolated type II SLAP lesions: biceps tenodesis as an alternative to reinsertion. Am J Sports Med. 2009;37(5):929-36.

11. McFarland EG, Kim TK, Savino RM. Clinical assessment of three common tests for superior labral anterior-posterior lesions. Am J Sports Med. 2002;30(6):8105.

12. Sassmannshausen G, Sukay M, Mair SD. Broken or dislodged poly-L-lactic acid bioabsorbable tacks in patients after SLAP lesion surgery. Arthroscopy. 2006;22(6):615-9.

13. Nam EK, Snyder SJ. The diagnosis and treatment of superior labrum, anterior and posterior (SLAP) lesions. Am J Sports Med. 2003;31(5):798-810.

14. Kartus J, Kartus C, Brownlow H, Burrow G, Perko M. Repair of type-2 SLAP lesions using Corkscrew anchors. A preliminary report of the clinical results. Knee Surg Sports Traumatol Arthrosc. 2004;12(3):229-34.

15. Ifesanya A, Scheibel M. Posterosuperior suture granuloma impingement after arthroscopic SLAP repair using suture anchors: a case report. Knee Surg Sports Traumatol Arthrosc. 2008;16(7):703-6.

16. Ide J, Maeda S, Takagi K. Sports activity after arthroscopic superior labral repair using suture anchors in overhead-throwing athletes. Am J Sports Med. 2005;33(4):507-14.

17. Yoo JC, Lee YS, Ahn JH, Park JH, Kang HJ, Koh KH. Isolated suprascapular nerve injury below the spinoglenoid notch after SLAP repair. J Shoulder Elbow Surg. 2009;18(4):e27-9. quent complication in group 1 was adhesive capsulitis $(55.6 \%)$, whereas it was residual pain in group $2(83.3 \%)$.

\section{CONCLUSION}

In our study, SLAP lesions presented a major association with other shoulder lesions (96\%): labral lesions in patients aged under 40 years and impact syndrome with or without rotator cuff lesions in patients aged 40 years or over. Arthroscopic repair of SLAP lesions provided results classified as good or excellent in $79 \%$ of the cases, and $21 \%$ presented complications, among which residual pain and adhesive capsulitis were the most frequent ones. Because of the small number of cases, we cannot reach any conclusion in relation to the results from repairs on SLAP lesions alone.
18. Resch H, Golser K, Thoeni H, Sperner G. Arthroscopic repair of superior glenoid labral detachment (the SLAP lesion). J Shoulder Elbow Surg. 1993;2(3):14755.

19. Ejnisman B, Andreoli CV, Pochini AC, Monteiro GC, Faloppa F, Cohen M. Artropatia glenoumeral pós-tratamento de lesões labiais com implantes metálicos. Rev Bras Ortop. 2006;41(5):167-72.

20. Ellman H, Hanker G, Bayer M. Repair of the rotator cuff. End-result study of factors influencing reconstruction. J Bone Joint Surg Am. 1986;68(8):1136-44.

21. Hawkins RJ, Bokor DJ. Clinical evaluation of shoulder problems. In: Rockwood CA Jr, Matsen FA 3rd, editors. The shoulder. 2nd ed. Saint Louis: Saunders; 1998. p. 164-98.

22. Kim SH, Ha KI, Kim SH, Choi HJ. Results of arthroscopic treatment of superior labral lesions. J Bone Joint Surg Am. 2002;84(6):981-5.

23. Rhee YG, Lee DH, Lim CT. Unstable isolated SLAP lesion: clinical presentation and outcome of arthroscopic fixation. Arthroscopy. 2005;21(9):1099-104.

24. Brockmeier SF, Voos JE, Williams RJ 3rd, Altchek DW, Cordasco FA, Allen AA; Hospital for Special Surgery Sports Medicine and Shoulder Service. Outcomes after arthroscopic repair of type-II SLAP lesions. J Bone Joint Surg Am. 2009;91(7):1595-603.

25. Neri BR, Vollmer EA, Kvitne RS. Isolated type II superior labral anterior posterior lesions: age-related outcome of arthroscopic fixation. Am J Sports Med. 2009;37(5):937-42.

26. Katz LM, Hsu S, Miller SL, Richmond JC, Khetia E, Kohli N, Curtis AS. Poor outcomes after SLAP repair: descriptive analysis and prognosis. Arthroscopy. 2009;25(8):849-55

27. Voos JE, Pearle AD, Mattern CJ, Cordasco FA, Allen AA, Warren RF. Outcomes of combined arthroscopic rotator cuff and labral repair. Am J Sports Med. 2007;35(7):1174-9.

28. Coleman SH, Cohen DB, Drakos MC, Allen AA, Williams RJ, O'brien SJ, Altchek DW, Warren RF. Arthroscopic repair of type II superior labral anterior posterior lesions with and without acromioplasty: a clinical analysis of 50 patients. Am J Sports Med. 2007;35(5):749-53.

29. Keener JD, Brophy RH. Superior labral tears of the shoulder: pathogenesis, evaluation, and treatment. J Am Acad Orthop Surg. 2009;17(10):627-37.

30. Kim TK, Queale WS, Cosgarea AJ, McFarland EG. Clinical features of the different types of SLAP lesions: an analysis of one hundred and thirty-nine cases. J Bone Joint Surg Am. 2003;85-A(1):66-71.

31. Khetia EA, Curtis A, Miller S. Factors of failure in SLAP repair. Arthroscopy. 2007;23:e26.

32. Franceschi F, Longo UG, Ruzzini L, Rizzello G, Maffulli N, Denaro V. No advantages in repairing a type II superior labrum anterior and posterior (SLAP) lesion when associated with rotator cuff repair in patients over age 50: a randomized controlled trial. Am J Sports Med. 2008;36(2):247-53. 